\title{
On the alleged convenience of chemical weed control in row crops in the Midwest
}

\author{
Jim Bender
}

Is chemical weed control in row crops more convenient than non-chemical weed control? Does it solve more problems or create fewer problems than the non-chemical alternative? Convenience is usually assumed to be the strong point of chemical weed control. I challenge this assumption. Here are some of the issues and problems of alternative systems of weed control in the context of a complete planting season. The force of my challenge will be the sum of considerations interspersed through four stages of a planting season.

Early spring

Machinery requirements are central to weed control decisions prior to the beginning of spring work. Non-chemical weed control (NCWC) requires none of the machinery associated with herbicide application. Chemical weed control (CWC) occasionally requires all the weed control machinery of NCWC. A rotary hoe and a row crop cultivator are minimally sufficient weed control machinery for NCWC. CWC requires some combination of the following spraying equipment: booms on tillage equipment, tanks on tractor(s), a general sprayer, and liquid handling equipment. In addition, almost all CWC systems include a row crop cultivator to manage uncertainties in chemical control and a rotary hoe to cope with crusting problems and herbicide failure. Whether the rotary hoe is owned, rented, or custom hired, it must be taken into account when planning a CWC system.

Another decision at this time of year concerns the location of crops. A CWC system is much more restrictive because of herbicide carryover. Issues include compatibility between this year's crop and last year's herbicide, living with herbicidestressed crops when compatibility is misjudged, and sometimes being prevented from planting a particular crop in a field. One example is the incompatibility of oats with triazine herbicides. NCWC faces no such problems.

Middle spring

Primary concerns in spring tillage are weed control and seedbed preparation. CWC systems with pre-plant herbicides add

NE

Jim Bender is an organic farmer near Weeping Water, the need for herbicide incorporation. The problem, from the perspective of convenience, is that herbicide incorporation cannot always be combined with another tillage operation. For example, operators sometimes till a field just to incorporate the herbicide and sometimes till a field twice to enhance the incorporation. Nothing is gained by extra tillage except incorporation.

How much attention to detail in tillage do the alternative systems require? For NCWC the final tillage prior to planting must be thorough, both to control weeds and to enhance uniform germination. Requirements of pre-plant herbicide incorporation include completely uniform application. Missed spots result in no weed control. Overlaps increase herbicide costs and may increase herbicide stress on the crop. Uniform application also requires accurate tank mixes and correctly calibrated sprayer nozzles. CWC is more complicated and less convenient than NCWC at this stage of the planting season.

\section{Planting time}

Each method of weed control may place stress on the crops. With NCWC the potential for stress is the rotary hoeing(s), which tears out some of the crop seedlings. For CWC the potential problem is herbicide stress. Only NCWC, however, permits compensatory measures. An operator can increase the planting rate to compensate for thinning by the rotary hoe. In contrast, CWC permits no way to compensate.

Planting places demands on a farmer's resources, and farming at this time of year is complicated by CWC. Most chemical systems involve application of herbicides at some stage of planting, whether it is pre-plant incorporation by the tillage tractor, application with the planter unit, or pre-emergence applications. In addition, the herbicide applicator who rigorously follows label and EPA instructions bears the burden of cumbersome protective clothing and other measures. NCWC systems are free of all these concerns at this acutely busy time.

Post planting

Shortly after planting, the fine-tuned weed control of NCWC systems must begin. The inherent advantage of this method is

Continued on page 144

American Journal of Alternative Agriculture 
OPINION--Continued from page 98

that it can be applied as needed. NCWC can capitalize on favorable conditions to reduce costs, work, and management. For example, if rainfall is delayed after planting, conditions have permitted me to complete effective weed control with one rotary hoeing and one cultivation. In contrast, CWC systems are committed to the cost of herbicide before post-planting conditions are known. CWC has no flexibility to capitalize on cost-saving opportunities.

Crusting is one problem after planting. For CWC systems, breaking a crust with a rotary hoe is a wholly additional cost. For NCWC systems, the crust-breaking tillage can be an additional benefit of the first scheduled rotary hoeing, so that its cost can be disregarded.

Another threat is early crop failure from many causes: heavy rain, hail, lost weed control, or plant diseases. Crop failure may create two problems peculiar to CWC. The first is the inflexibility of herbicides discussed above. For NCWC, crop failure means that some weed control costs can be avoided. The other potential problem after crop failure is herbicide incompatibility between the lost crop and the replacement crop. Suppose that a field of milo is destroyed by hail on approximately June 15. The most obvious planting option available would be soybeans. There is a good possibility that soybeans would be incompatible with the milo herbicide. Even if the damaged crop is replaced with the same crop, it is difficult to determine whether enough of the original herbicide remains or whether a second application would be too much.

Two additional notorious problems of $\mathrm{CWC}$ are herbicide drift and weed resistance to herbicides. Herbicide drift can damage the applicator's other crops as well as those of neighbors. NCWC has no potential to harm other crops. The fast developing problem of weed resistance to herbicides continues to include more kinds of weeds and expand to more areas of the United States, another problem unique to CWC systems.

Conclusion

CWC generates problems at every stage of the growing season. Problems peculiar to this system include crop rotation restrictions, greater machinery costs, possibly extra pre-plant tillage, a small margin for error in application, herbicidestressed crops, application demands at the busy planting time, inflexibility in coping with various crop conditions after planting, herbicide drift, and weed resistance to herbicides.

NCWC is beset with its own significant challenges. Concerns include informed diversified crop rotation, lengthened planting dates to coordinate the workload of mechanical weed control, and meticulous timing and application of mechanical weed control. Further, extremely wet growing seasons challenge NCWC and reduce the farmer's options. It is important to note, however, that these special concerns are surmounted by learning new skills and better management, not by additional capital outlays.

It is not clear how to tally which system "wins" this competition. I have described how chemical weed control--advertised as convenient in making weed control easier--causes numerous complications, inefficiencies, and unresolvable problems, which do not plague chemical free weed control approaches with row crops.

\section{UPCOMING EVENTS}

March 11-14. International Conference on Agriculture and the Environment at Columbus, Ohio. Organized by The Ohio State University. Environmental, ecological, economic, and social issues are focus. For more information, call (614) 292-8209.

March 15-17. Food safety and pesticide poisoning are key topics at the Pesticide Forum, a 10th anniversary event sponsored by the National Coalition Against the Misuse of Pesticides (NCAMP). Information is available from NCAMP at 701 E Street, SE, Washington, DC 20004, 543-5450.

March 18-20. Farming for the Future: In-Service Training in Organic and Sustainable Agriculture, to be held on the Cornell University Campus, Ith- aca, New York. Sponsored by the Northeast Organic and Sustainable Farmers Network. Open to extension, USDA, and other agriculture professionals. For registration information, contact Judy Green, Cornell Farming Alternatives Program, (607) 255-9832.

March 21-22. A symposium on Prospects for Lupins in North America. Ramada Hotel, St. Paul, Minnesota. Sponsored by Minnesota Extension Service. For information, call Extension Special Programs at (800) 367-5363 or (612) 625-2722.

April 9-11. Use of Cover Crops for Erosion Control is focus of a Soil and Water Conservation Society Spring Conference at Jackson, Tennessee. Contact the Society at 7515 Northeast Ankeny Road, Ankeny, IA 50021,
(515) 289-2331.

\section{LETTERS TO THE EDITOR INVITED}

The AJAA welcomes letters, short or long, commenting on articles in this journal or sharing ideas likely to be of interest to other AJAA readers. Since our space is limited, we do reserve the right not to publish all letters or, at times, to publish only excerpts from them. To take part in this exchange of ideas, write to: Editor, AJAA, $9200 \mathrm{Ed}$ monston Road, Suite 117, Greenbelt, MD 20770. 